\title{
trabahonecessário
}

iss $\mathrm{n:} 1808-799 \mathrm{X}$

ano 1 - número 1 - 2003

\section{O SIGNIFICADO DO TRABALHO NO CAPITALISMO E O TRABALHO COMO PRINCÍPIO EDUCATIVO: ENSAIO DE ANÁLISE CRÍTICA}

THE MEANING OF LABOUR IN THE CAPITALISM AND THE LABOUR AS AN EDUCATIVE PRINCIPLE: A TENTATIVE CRITICAL ANALYSIS

TUMOLO, Paulo Sergio

tumolo@ced.ufsc.br

RESUMO: O texto tem como finalidade analisar criticamente a concepção do trabalho como princípio educativo, que tem sido utilizada para fundamentar propostas de educação dos mais importantes movimentos sociais brasileiros, tais como o MST e a CUT. À luz da contribuição teórica oferecida por Marx, sobretudo em O Capital, discute o significado das três categorias fundantes de trabalho - trabalho concreto, trabalho abstrato e trabalho produtivo -, bem como a relação de contradição que ocorre entre elas, e demonstra que, se o trabalho, numa forma social genérica, é o elemento determinante na constituição da própria natureza humana, no capitalismo a construção do gênero humano, por intermédio do trabalho, se dá pela sua destruição, sua emancipação se efetiva pela sua degradação, a afirmação de sua condição de sujeito se realiza pela negação desta mesma condição, sua hominização ocorre pela produção de sua reificação. No limite, trata-se da constituição do fetiche do capital - o capital que se subjetiviza ou se hominiza reificando as relações sociais e o ser social. Dado o conjunto de argumentos apresentados, o texto questiona o trabalho como princípio educativo como proposta de uma estratégia político-educativa que tenha uma perspectiva emancipadora.

Palavras-chave: trabalho, educação, capital, capitalismo, fetiche do capital.

ABSTRACT: The text aims at critically analysing the concept of labour as educative principle, which has been used to support educational proposals by the most important Brazilian social movements, namely the MST and CUT. Based on the theoretical contribution by Marx, in particular in The Capital, it discusses the meaning of three founding categories of labour - concrete useful labour, abstract human labour, and productive labour - as well as the contradiction relation occurring among them, and shows that, if the labour, in a generic social form, is the determining element for the constitution of very human nature, in the capitalism the constitution of humankind, by means of labour, occurs through its own destruction, its emancipation realizes itself in its degradation, the affirmation of its condition as a subject realizes itself in the negation of this condition, its humanisation occurs by the production of its reification. Ultimately, it concerns the constitution of the fetishism of the capital - the capital that becomes subject or human reifying the social relations and the social being. Due to the array of arguments presented, the text challenges the labour as an educative principle as a proposal in terms of a political-educational strategy in an emancipating perspective.

Key words: labour, education, capital, capitalism, fetishism of the capital 
Alguns movimentos sociais, que têm ocupado papel central no cenário político brasileiro contemporâneo, vêm buscando desenvolver, em seu seio, propostas de educação que se pretendem inovadoras e progressistas, balizadas pelo lema do trabalho como princípio educativo. Tal é o caso, pelo menos, do Movimento dos Trabalhadores Rurais Sem-Terra, o MST (1), e da Central Única dos Trabalhadores, a CUT (2). Como se trata apenas de um lema, que carece de precisão e consistência teóricas, as concepções a seu respeito são as mais variadas e desencontradas (3), o que o torna um assunto, no mínimo, controvertido. Ademais, a proposição tem sido alvo de tantas discussões, principalmente na CUT a partir da segunda metade dos anos 90 quando esta começou a implantar seus projetos de formação profissional, que merece ser analisada com mais atenção e profundidade.

Antes, porém, de ter se tornado um elemento basilar de propostas educacionais de movimentos sociais, 0 trabalho como princípio educativo, no bojo das análises acerca da relação entre educação e trabalho, foi um dos temas mais recorrentes no Brasil, nos anos 80 e início dos 90 do século XX, entre os pensadores da educação, sobretudo aqueles que se apoiavam num referencial teórico-político marxista, com enfoque em Gramsci (4). Como escapa aos propósitos deste texto apresentar as abordagens realizadas pelos numerosos autores que se ocuparam do assunto5, destacarei uma citação de um deles, uma vez que sintetiza a concepção presente no conjunto de seus estudiosos e serve de base, em grande medida, para as propostas educativas dos referidos movimentos sociais. Num trecho de uma entrevista concedida à Revista Bimestre, Saviani assim resume os fundamentos conceituais da proposição do trabalho como princípio educativo:

"Na verdade, todo sistema educacional se estrutura a partir da questão do trabalho, pois o trabalho é a base da existência humana, e os homens se caracterizam como tais na medida em que produzem sua própria existência, a partir de suas necessidades. Trabalhar é agir sobre a natureza, agir sobre a realidade, transformando-a em função dos objetivos, das necessidades humanas. A sociedade se estrutura em função da maneira pela qual se organiza o processo de produção da existência humana, o processo de trabalho" (Saviani, 1986a:14).

Se é verdade que o trabalho é a base da existência humana, penso que seria necessário indagar como é produzida esta existência humana, por intermédio do trabalho, na especificidade do modo capitalista de produção. Qual é, nesta forma social determinada, o significado do trabalho? Em que medida seria possível considerar o trabalho como princípio balisador de uma proposta emancipadora de educação no interior do capitalismo?

Motivado por essas questões, o presente texto tem como finalidade examinar o referido tema, mesmo que de forma introdutória e ensaística, dando ênfase no significado do trabalho, sobretudo no modo capitalista de produção, à luz da contribuição teórica oferecida por Marx.

\section{BASES ANALÍTICAS PARA A COMPREENSÃO DO SIGNIFICADO DO TRABALHO NO CAPITALISMO}

Não cabe num ensaio desta natureza fazer uma exegese de todas as obras em que Marx tratou da questão do trabalho, o que poderia demonstrar a evolução do seu pensamento a esse respeito. Penso, contudo, que seria necessário explicitar, mesmo que limitadamente, o caminho analítico, ou seja, o método de exposição (6) que o autor adotou em sua principal obra, O Capital, com o escopo de apreender a construção teórica que faz acerca do trabalho.

O ponto de partida da análise que Marx desenvolve em O Capital é a noção de riqueza (7), numa clara alusão aos principais pensadores da economia política clássica, sobretudo a Adam Smith (8), tendo em vista que seu objetivo principal era o de proceder a 'crítica da economia política'. Não por acaso este foi o subtítulo de sua obra capital. Desde o início, para fazer a crítica, Marx historiciza seu objeto de investigação, compreendendo-o não como qualquer riqueza de qualquer sociedade, mas sim aquela em que domina o modo de produção capitalista, que, por esta razão, aparece como uma "imensa coleção de mercadorias". Somente a partir desse pressuposto, dessa historicização, é que a "investigação começa com a análise da mercadoria", por intermédio de seus dois fatores: valor de uso e valor.

Entre os diversos aspectos do emaranhado analítico desenvolvido no capítulo primeiro (9), Marx busca explicar não apenas a relação de contradição entre o valor de uso e o valor de troca, já que a realização deste último, na troca, é a sua negação e, ao mesmo tempo, a afirmação do valor de uso, mas, acima de tudo, o movimento contraditório existente entre o valor de uso e o valor, que se origina do duplo caráter do trabalho, uma vez que o desenvolvimento da força produtiva do trabalho propicia a produção de uma quantidade maior de valores de uso, quer dizer, um montante maior de riquezas com um quantum menor de valor. A mesma variação crescente de força produtiva do trabalho que aumenta a riqueza, diminui a grandeza de valor contida nessa massa de riqueza. Tendo em vista que o trabalho concreto é o substrato do valor de uso e o trabalho abstrato é a substância do valor, eles também estabelecem uma relação de 
contradição. Num primeiro exercício analítico se percebe que o trabalho concreto (valor de uso) está subsumido pelo trabalho abstrato (valor), em razão de que o capitalismo é uma sociedade essencialmente mercantil, cujo objetivo não é a produção de valores de uso para a satisfação das necessidades humanas, do estômago à fantasia. Mais do que isto, se trata de uma relação na qual a afirmação do trabalho abstrato é a negação do trabalho concreto e vice-versa. O desenvolvimento da força produtiva do trabalho, que é uma tendência inelutável do capital, agudiza tal contradição.

Sendo a mercadoria a principal célula do organismo, ou melhor, a particularidade central na totalidade do capital, Marx se empenha, na seção I de O Capital, em estudá-la e explicitar ao mesmo tempo tanto suas contradições, que já expressam embrionariamente as contradições do movimento do capital, como seu caráter fetichista, o que lhe permite também explicar o dinheiro como meio de circulação de mercadorias, e desvendar o fetichismo do dinheiro, uma vez que a forma equivalente geral, ou melhor, a forma dinheiro se reduz, em última instância, à forma mercadoria simples ou, se se quiser, a forma mercadoria simples é o germe da forma dinheiro.

Na seção seguinte, composta apenas pelo capítulo quatro, o autor dá início à explicação de como o dinheiro, de equivalente geral e meio circulante, se transforma em capital. A forma direta de circulação de mercadorias, $M-D-M$, se transmuta na fórmula geral do capital, $D-M-D$ '. A primeira forma, a da circulação simples, tem como objetivo a troca de mercadorias, intermediada pelo dinheiro, que se transformam para seus oponentes em valores de uso e, dessa maneira, satisfazem suas respectivas necessidades, saindo da esfera da circulação. Na segunda forma, ao contrário, parte-se de um montante em dinheiro, compra-se e vende-se mercadoria, com a finalidade de, ao final do processo, obter-se mais dinheiro, ou mais valor (mais-valia) (10), em relação àquele inicial, mantendo-se e reforçando-se, assim, a esfera da circulação. De fato, " $D-M-D$ ' é a fórmula geral do capital, como aparece diretamente na esfera da circulação" (Marx, 1983 : 131). Não se trata, todavia, do lucro isolado, mas do incessante e insaciável movimento de ganho, de valorização do valor.

Sob o título de contradições da fórmula geral, Marx elenca um conjunto de argumentos para demonstrar que a valorização do valor, ou seja, o capital não pode ter origem na esfera da circulação, tendo em vista que o intercâmbio de mercadorias não produz valor e, por conseguinte, mais-valia. Por outro lado, contraditoriamente, é impossível que o dinheiro se transforme em capital fora da esfera da circulação. "Capital não pode, portanto, originar-se da circulação e, tampouco, pode não originar-se da circulação. Deve, ao mesmo tempo, originar-se e não se originar dela" (Idem : 138).

Grosso modo, o autor argumenta que a transformação do dinheiro em capital não pode provir, em hipótese alguma, da circulação simples de mercadorias, qualquer que seja sua forma, mas exclusivamente do intercâmbio de uma mercadoria única e específica, qual seja, a força de trabalho, já que a utilização de seu próprio valor de uso tem a característica peculiar e exclusiva de ser fonte de valor. Não é por outra razão que, na seqüência, discorre sobre o valor da força de trabalho (11), que corresponde a um determinado quantum de trabalho abstrato socialmente necessário para produzir a massa de meios de subsistência necessária para a produção e reprodução normais da vida do trabalhador e de sua família, e encerra o capítulo apresentando a cena na qual os personagens do drama, capitalista e proletário, estabelecem o contrato de compra e venda da força de trabalho, prenunciando, de maneira inteligentemente irônica, que é por intermédio desta relação contratual, na qual são cumpridos todos os preceitos liberais, que o trabalhador "leva sua pele para o curtume para ser esfolado".

\section{VIRAGEM E REVIRAGEM NO MÉTODO DE EXPOSIÇÃO DE O CAPITAL}

Com a finalização da seção II, composta pelo capítulo quatro, praticamente todos os elementos para a elucidação do segredo da transformação do dinheiro em capital estão postos. Se tal segredo se localiza na compra e venda da força de trabalho, era de se supor que Marx iniciasse o próximo capítulo examinando imediatamente a relação de troca desta mercadoria. Surpreendentemente, tal não se sucede. O capítulo cinco é dividido em duas partes, a saber, o processo de trabalho e o processo de valorização. O que chama a atenção, de início, é o fato de que o autor, no primeiro segmento, faz um caminho analítico inverso àquele que havia adotado desde o princípio.

De forma resumida, o método de exposição de Marx nos quatro primeiros capítulos de O Capital tem como início a riqueza, ou o valor de uso, e já que "a riqueza das sociedades em que domina o modo de produção capitalista aparece como uma 'imensa coleção de mercadorias' e a mercadoria individual como sua forma elementar" (Idem:45), sua análise se focaliza na mercadoria (M) e seus dois fatores, valor de uso e valor. Tendo em vista que a mercadoria só pode ser apreendida na relação com outra mercadoria, o autor busca estudar a relação $M-M$, desde a forma simples de valor, passando pela forma geral de valor, até chegar na forma dinheiro (D), como equivalente geral, (e sua expressão monetária, a forma preço), ou seja, na 
relação $M-D$, o que lhe possibilita desvendar, a um só tempo, o enigma do fetiche da mercadoria e do dinheiro. Do dinheiro como equivalente geral $(M-D)$, o autor salta para a explicação do dinheiro como meio circulante, que se apresenta na fórmula $M-D-M$, e que se desdobra em $M-D$ (venda) e $D-M$ (compra), cujo processo, em seu conjunto, forma a circulação de mercadorias. A realização proporcionalmente maior da primeira fase $(M-D)$ em relação à segunda $(D-M)$, ou seja, vender 0 máximo possível e comprar o mínimo necessário, resultando num acúmulo de dinheiro, propicia o surgimento do entesourador, que é a antítese do capitalista (12). Por outro lado, a possibilidade de realização da segunda fase $(D-M)$ antes da efetivação da primeira $(M-D)$, que só ocorrerá a posteriori denota o surgimento do dinheiro como meio de pagamento e, por decorrência, do credor e do devedor. Enquanto que o entesouramento tende a desaparecer com o progresso da sociedade burguesa, uma vez que ele é a negação do capital, a possibilidade da existência dessa segunda metamorfose (D - M) a priori cria as condições para o surgimento do capitalista embrionário, que irá comprar a força de trabalho antes de pagála, tornando-se devedor do trabalhador e este credor do capitalista. De fato, esta segunda fase é o ponto de partida da fórmula do capital, $D-M-D$ ', que expressa a transformação do dinheiro em capital (13).

O método de exposição percorrido até o capítulo quatro foi o de partir da riqueza, penetrar no estudo da mercadoria e do dinheiro como meio circulante e chegar, ainda que embrionariamente, no dinheiro como capital, ou seja, o itinerário que vai da riqueza ao capital e, portanto, do valor de uso - passando pelo valor de troca - ao valor, e, deste, à mais-valia - mesmo que apenas anunciada sem ter sido, ainda, explicada — , ou, se se quiser, o caminho vai do trabalho concreto ao trabalho abstrato (14). Marx busca dar concreticidade à sua análise, quer dizer, todas as categorias utilizadas são categorias que buscam apreender o fenômeno do capital e, por essa razão, elas só têm validade explicativa numa forma social determinada, a capitalista. Na primeira parte do capítulo cinco, ao contrário, o autor tece um percurso oposto. Ele começa discorrendo sobre a utilização da força de trabalho que, para cumprir sua finalidade para o capitalista produzir valor e, por conseguinte, mais-valor - deve produzir, antes de tudo, valores de uso. Tendo em vista que a produção de valores de uso não muda sua natureza geral por se realizar para o capitalista, "o processo de trabalho deve ser considerado de início independentemente de qualquer forma social

determinada" (Idem : 149). O caminho percorrido, expresso logo no início do capítulo, é o que vai do capital à riqueza, ou da força de trabalho, que pressupõe a produção do valor, ao valor de uso, qual seja, do trabalho abstrato ao trabalho concreto e, deste, ao trabalho em geral, considerado como elemento mediador da relação metabólica entre o ser humano e a natureza, independentemente de qualquer forma social determinada. Diferentemente do que ocorrera anteriormente, aqui Marx parte de categorias analíticas específicas para a apreensão do capital e do seu modo de produção para chegar em categorias analíticas de caráter genérico que tratam de uma forma social genérica e, por conseguinte, de um ser social também genérico. É dentro desta compreensão que ele explicita a noção de trabalho em geral.
"Antes de tudo, o trabalho é um processo entre o homem e a Natureza, um processo em que o homem, por sua própria ação, media, regula e controla seu metabolismo com a Natureza. Ele mesmo se defronta com a matéria natural como uma força natural. Ele põe em movimento as forças naturais pertencentes à sua corporalidade, braços e pernas, cabeça e mão, a fim de apropriar-se da matéria natural numa forma útil para sua própria vida. Ao atuar, por meio desse movimento, sobre a Natureza externa a ele e ao modificá-la, ele modifica, ao mesmo tempo, sua própria natureza. Ele desenvolve as potências nela adormecidas e sujeita o jogo de suas forças a seu próprio domínio. Não se trata aqui das primeiras formas instintivas, animais, de trabalho. $O$ estado em que o trabalhador se apresenta no mercado como vendedor de sua própria força de trabalho deixou para o fundo dos tempos primitivos o estado em que o trabalho humano não se desfez ainda de sua primeira forma instintiva. Pressupomos o trabalho numa forma em que pertence exclusivamente ao homem. Uma aranha executa operações semelhantes às do tecelão, e a abelha envergonha mais de um arquiteto humano com a construção dos favos de suas colméias. Mas o que distingue, de antemão, o pior arquiteto da melhor abelha é que ele construiu o favo em sua cabeça, antes de construí-lo em cera. No fim do processo de trabalho obtém-se um resultado que já no início deste existiu na imaginação do trabalhador, e portanto idealmente. Ele não apenas efetua uma transformação da forma da matéria natural; realiza, ao mesmo tempo, na matéria natural seu objetivo, que ele sabe que determina, como lei, a espécie e o modo de sua atividade e ao qual tem de subordinar sua vontade. E essa subordinação não é um ato isolado. Além do esforço dos órgãos que trabalham, é exigida a vontade orientada a um fim, que se manifesta como atenção durante todo o tempo de trabalho, e isso tanto mais quanto menos esse trabalho, pelo próprio conteúdo e pela espécie e modo de sua execução, atrai o trabalhador, portanto, quanto menos ele o aproveita, como jogo de suas próprias forças físicas e espirituais (15). Os elementos simples do processo de trabalho são a atividade orientada a um fim ou o trabalho mesmo, seu objeto e seus meios" (Marx, 1983:149-50).

As questões que se impõem são, por decorrência, as que se seguem. Por que Marx opera essa inversão metodológica? Por que, depois de construir, consistente e cuidadosamente, as categorias analíticas 
específicas referentes ao capital e tecer suas contraditórias relações, o autor efetua uma viragem e lança mão de categorias analíticas de natureza genérica? Com o intuito de tentar dar respostas a tais interrogações, sugiro a hipótese segundo a qual o autor está fazendo uma espécie de digressão, um interregno analítico no curso normal de seu método buscando atingir, entre outros, dois objetivos: 1) apresentar o último elemento constitutivo da relação capitalista de produção, a saber, os meios de produção, e 2) explicitar, distinguir e, ao mesmo tempo, estabelecer a conexão entre o processo de trabalho, processo de formação de valor e processo de valorização.

No final do capítulo quatro o fator determinante para a transformação do dinheiro em capital já havia sido exposto - a força de trabalho. Porém, a produção de mercadorias e, conseqüentemente, de capital só pode se efetivar quando o capitalista compra a força de trabalho e esta encontra os meios de produção necessários para atingir os objetivos do capitalista. Ora, a produção do capital só se realiza na medida em que o capitalista consome o valor de uso da força de trabalho, o que só ocorre sob a condição de a força de trabalho consumir o valor de uso dos meios de produção, quer dizer, quando se estabelece a articulação orgânica entre a força de trabalho e os meios de produção, entre o capital variável e o capital constante.

Todavia, o encontro entre força de trabalho e meios de produção, cuja finalidade é produzir valores de uso, não tem, em princípio, um caráter capitalista, uma vez que tal relação é condição eterna da humanidade para produzir sua vida em qualquer forma societal. Por essa razão, de início, Marx dá um tratamento genérico aos meios de produção no bojo do processo de trabalho, já que, de per si, eles não têm uma natureza capitalista e só 'adquirem' este conteúdo histórico quando a força de trabalho que os utiliza se transformou numa mercadoria, ou seja, quando se estabelece a relação especificamente capitalista, cuja condição essencial é a conversão da força de trabalho em mercadoria. Em suma, neste momento de sua trajetória analítica, o autor está fazendo uma explanação do 'processo simples de trabalho'.

A hipótese aqui levantada parece se confirmar ao se fazer uma leitura atenta do primeiro segmento do capítulo cinco. Depois de versar sobre o trabalho em geral, o autor discorre, de forma também genérica, acerca dos meios de produção - articulação de meios e objetos de trabalho - , que devem servir como elementos do processo cuja finalidade é a produção de valores de uso para a satisfação de necessidades humanas. "Considerando-se o processo inteiro do ponto de vista de seu resultado, do produto, aparecem ambos, meio e objeto de trabalho, como meios de produção, e o trabalho mesmo como 'trabalho produtivo'" (idem:151, grifado por mim). Referendando a hipótese aventada, Marx escreve uma nota de rodapé na qual esclarece que "essa determinação de trabalho produtivo, tal como resulta do ponto de vista do 'processo simples de trabalho', não basta, de modo algum, para o 'processo de produção capitalista'” (16) (idem, ibidem, grifado por mim).

Buscando oferecer uma visão de conjunto acerca do tema abordado na primeira parte do capítulo cinco, o autor assevera que

"o processo de trabalho, como o apresentamos em seus elementos simples e abstratos (17), é atividade orientada a um fim para produzir valores de uso, apropriação do natural para satisfazer a necessidades humanas, condição universal do metabolismo entre o homem e a Natureza, condição natural eterna da vida humana e, portanto, independente de qualquer forma dessa vida, sendo antes igualmente comum a todas as suas formas sociais" (idem:153).

Percebe-se claramente, portanto, que Marx está analisando os elementos constitutivos do processo simples de trabalho, que, embora necessários, são insuficientes para se entender o processo de produção do capital. Por essa razão, as categorias analíticas aqui utilizadas - entre elas, o trabalho, ou trabalho em geral e também o trabalho produtivo na acepção dada - carecem de força e conteúdo explicativo quando se trata de qualquer forma social determinada, inclusive a capitalista. Para ser mais preciso, tais categorias têm um caráter genérico e são insuficientes para explicar o processo de produção capitalista.

Tão logo foi cumprido um dos objetivos dessa 'digressão analítica' - a apresentação dos meios de produção no bojo do processo simples de trabalho -, o autor recupera a uma só vez tanto o curso analítico que havia sido suspenso no início do capítulo cinco, ou seja, seu método original, como as categorias analíticas presentes nos capítulos anteriores com o fito de continuar a investigação e, dessa forma, buscar desvendar a produção do capital. Em outras palavras: uma vez que apresentou os meios de produção no bojo do processo simples de trabalho, Marx executa uma nova 'viragem metodológica' (18) e retoma a análise interrompida trazendo de volta a força de trabalho como mercadoria e, por conseguinte, os atores sociais que estabelecem a relação de troca desta mercadoria. "Voltemos ao nosso capitalista in spe (em aspiração)", afirma o autor. "Deixamo-lo logo depois de ele ter comprado no mercado todos os fatores necessários a um processo de trabalho, os fatores objetivos ou meios de produção e o fator pessoal ou a força de trabalho" (idem:154). Mediante a compra da força de trabalho, o capitalista "incorporou o próprio trabalho, 
como fermento vivo, aos elementos mortos constitutivos do produto, que lhe pertencem igualmente" (idem, ibidem). Finalmente, partindo do 'processo simples de trabalho', todos os elementos para a compreensão do 'processo de produção capitalista' estão dados, e seu desenvolvimento é retomado no segundo segmento do capítulo cinco, denominado, não por acaso, de processo de valorização. Aqui, o autor se propõe a examinar "o trabalho sob um aspecto totalmente diverso daquele sob o qual [foi considerado] durante o processo de trabalho" (idem:156). Lá, se tratava da atividade orientada ao fim de transformar matéria natural em produto, ou seja, produzir valor de uso; agora se trata do processo de produção do capital, que pressupõe a produção da mais-valia, que demanda, por sua vez, a produção do valor, que só pode ocorrer por intermédio da produção do valor de uso.

Marx desvenda o segredo da produção do capital, ou do processo de valorização, ao lançar mão da categoria de mais-valia e explicar sua origem. O possuidor do dinheiro, o capitalista, vai ao mercado e compra, de um lado, os meios de produção pelo seu valor e de outro a força de trabalho, pagando também seu exato valor. O consumo do valor de uso da força de trabalho, que se efetiva quando esta consome os meios de produção, resulta na criação de uma mercadoria, propriedade do capitalista, que vai vendê-la pelo seu valor. A produção da mais-valia pressupõe o cumprimento do fundamento primordial do mercado, a troca das mercadorias pelo seu valor, quer dizer, a troca igualada entre proprietários de mercadorias (19), tendo em vista que, nesta relação de igualdade, a força de trabalho, e somente ela, tem a propriedade de produzir valor e, ademais, valor excedente em relação a seu próprio valor, qual seja, mais-valia. Por meio da troca da mercadoria força de trabalho e da produção da mais-valia, o mistério finalmente foi revelado. Dinheiro se transformou em capital.

Somente no final do capítulo cinco é que se pode perceber com mais clareza a razão pela qual Marx só lograria explicar o 'processo de trabalho', na sua especificidade, diferenciando-o do 'processo de formação de valor' e do 'processo de valorização', se fizesse aquela digressão na evolução da exposição de seus argumentos, ou melhor, aquela inversão metodológica presente na primeira parte do capítulo cinco. Por esse motivo é que lança mão de categorias genéricas, inclusive as de trabalho em geral e trabalho produtivo em geral. Depois de ressaltar as especificidades e distinções entre os três processos, o autor busca estabelecer conexões entre eles, compreendendo o processo de produção de mercadorias como unidade entre processo de trabalho e processo de formação de valor e, diferentemente, o 'processo de produção capitalista', forma capitalista da produção de mercadorias, como 'unidade do processo de trabalho e do processo de valorização'. Este último, cujo escopo é a produção de capital, se distingue do anterior, que tem como finalidade a produção apenas de mercadorias. Ambos se diferenciam do processo simples de trabalho, uma vez que este objetiva a produção somente de valor de uso, de riqueza e, por isso, não pressupõe nenhum dos outros dois processos. O processo de produção de mercadorias implica o processo de trabalho, mas não o processo de produção capitalista, e este, por sua vez, pressupõe os outros dois processos.

\section{O SIGNIFICADO DO TRABALHO NA FORMA CAPITAL E O TRABALHO COMO PRINCÍPIO EDUCATIVO}

O capítulo cinco expressa a primeira grande síntese no método de exposição de O Capital. Uma vez alcançado este patamar e com o complemento dos capítulos seguintes — que, juntos, compõem a seção que trata da produção da mais-valia absoluta — , Marx busca entender as contradições do processo de valorização por intermédio do estudo dos processos de trabalho, empreendimento realizado, sobretudo, nos capítulos onze a treze, nos quais se dedica à análise das diversas fases do desenvolvimento capitalista, da cooperação simples à grande indústria, passando pela manufatura. Contudo, embora tenha feito uma investigação cuidadosa e minuciosa das transformações que ocorreram nos processos de trabalho ao longo de vários séculos, o autor não tinha o objetivo de examinar os processos de trabalho em si, mas analisar a mais-valia relativa - tanto que o título da seção composta pelos referidos capítulos é "A produção da maisvalia relativa" - , ou melhor, como foi possível, por intermédio das mudanças operadas nos processos de trabalho e do controle exercido pelo capital sobre eles, se conseguir a diminuição do valor da força de trabalho e, por conseguinte, a implementação da mais-valia relativa, o que implicou, contraditoriamente, uma redução de seu preço, abaixo do valor, e, por desdobramento, a necessidade de extração da mais-valia absoluta. Tal processo ocorre de tal maneira que se reinicia e se reproduz continuamente, provocando um círculo gradual e ascensional de degradação do trabalho. A produção da mais-valia relativa, e sua imbricação com a mais-valia absoluta, neste movimento contraditório e destrutivo, são, pois, o tema investigado por Marx nesta seção de sua obra (20).

Na seqüência, confirmando a hipótese anteriormente proposta, o autor começa o capítulo quatorze afirmando que "o processo de trabalho foi considerado primeiramente em abstrato (ver capítulo V), independente de suas formas históricas, como processo entre o homem e a Natureza" (Marx, 1984:105), e reproduz aqui um parágrafo do capítulo cinco bem como a nota de rodapé a ele anexada relembrando o sentido ali conferido ao trabalho produtivo (21). Se lá, tal categoria fora entendida a partir do processo simples de trabalho, como criadora de valores de uso de diversas espécies, agora se trata de compreendê-la do ponto de vista do processo de produção capitalista. Para ele, 


\begin{abstract}
"a produção capitalista não é apenas produção de mercadoria, é essencialmente produção de mais-valia. $\mathrm{O}$ trabalhador produz não para si, mas para o capital. Não basta, portanto, que produza em geral. Ele tem de produzir mais-valia. Apenas é produtivo o trabalhador que produz mais-valia para o capitalista ou serve à autovalorização do capital. Se for permitido escolher um exemplo fora da esfera da produção material, então um mestre-escola é um trabalhador produtivo se ele não apenas trabalha as cabeças das crianças, mas extenua a si mesmo para enriquecer o empresário. O fato de que este último tenha investido seu capital numa fábrica de ensinar, em vez de numa fábrica de salsichas, não altera nada na relação. O conceito de trabalho produtivo, portanto, não encerra de modo algum apenas uma relação entre a atividade e efeito útil, entre trabalhador e produto do trabalho, mas também uma relação de produção especificamente social, formada historicamente, a qual marca o trabalhador como meio direto de valorização do capital (22). Ser trabalhador produtivo não é, portanto, sorte, mas azar" (Idem : 105,6).
\end{abstract}

Somente nesta parte de sua obra, Marx completa a trilogia a respeito do trabalho no capitalismo: 'trabalho concreto' como criador de valor de uso, 'trabalho abstrato' como substância de valor e, finalmente, 'trabalho produtivo de capital'. Numa leitura preliminar, este último deve ser considerado, entre eles, como a categoria analítica determinante, pois, além de pressupor os dois primeiros, expressa o conjunto de contradições do processo de produção especificamente capitalista. Todavia, se nesta seção completa a trilogia acerca do trabalho no capitalismo, o autor não encerra a análise do capital, em seu movimento contraditório de acumulação.

Na verdade, depois da construção teórica realizada nos capítulos um a cinco, quer dizer, do caminho analítico que vai do valor de uso (riqueza) à transformação do dinheiro em capital, e tendo em vista que este não pode ser entendido apenas como realização da fórmula $D-M-D^{\prime}$, ou seja, como lucro momentâneo e isolado, mas como incessante e insaciável movimento de valorização do valor, Marx se dedica, no restante de sua obra principal, a compreender, grosso modo, o complexo de contradições inerentes ao processo de acumulação de capital, cuja síntese se materializa nas crises de superprodução de capital. Como é impossível, dentro dos limites de um texto desta natureza, oferecer um tratamento adequado ao conjunto das contradições, privilegiarei a análise de algumas delas, de acordo com os objetivos deste estudo.

Tendo em vista duas das contradições básicas do movimento do capital, a saber, a concorrência intercapitalista - expressão da divisão social do trabalho no capitalismo - e a contradição entre as duas classes sociais fundamentais, burguesia e proletariado - materializada na divisão do trabalho na empresa capitalista (23) - , o desenvolvimento das forças produtivas se torna o fator decisivo e fundamental no processo de produção capitalista. Isto porque é por meio do desenvolvimento das forças produtivas, cujo efeito prático é o aumento da produtividade, que os capitalistas logram a diminuição do valor de suas respectivas mercadorias, o que Ihes propicia sua sobrevivência no mercado competitivo e, ao mesmo tempo, a redução do valor da mercadoria força de trabalho, que resulta na produção da mais-valia relativa, com a condição de que o incremento da produtividade tenha atingido as cadeias de fabricação dos meios de subsistência necessários para produzir a vida do trabalhador. Aumento de produtividade significa, entretanto, a produção de uma quantidade cada vez maior de valores de uso com uma grandeza relativamente menor de 'valor', o que é um problema gravíssimo para o capital, pois redunda na tendência de diminuição da taxa de lucro e de acumulação, já que capital é resultado de um processo de valorização do 'valor' e não de acúmulo de valor de uso, ou seja, de riqueza (24). Dessa forma, a solução para os capitais privados é um problema para o capital, uma vez que o mecanismo que propicia a sobrevivência dos capitais privados no mercado cria, contraditoriamente, as condições de produção da morte do capital. Capitais privados e capital estabelecem, portanto, uma relação de contradição, de tal sorte que a continuidade da existência deste último implica a destruição, pelo menos parcial, de capitais privados, e vice-versa.

Não obstante, tal fenômeno se apresenta justamente porque, dada a concorrência intercapitalista, há uma necessidade de diminuição do valor das mercadorias, o que só pode ser conseguido com o desenvolvimento das forças produtivas e, por conseguinte, com o aumento da produtividade, que exige, por sua vez, a utilização relativamente menor da força de trabalho, ou seja, o dispensamento tendencial desta mercadoria que entra no processo de produção como capital variável, em detrimento da crescente utilização relativa do capital constante, redundando no aumento da composição orgânica do capital e, por decorrência, numa diminuição de sua taxa de acumulação. Por essa razão, e tendo em vista que há uma redução relativa do número de trabalhadores a serem explorados, o capital se vê constrangido a diminuir constantemente o preço da força de trabalho, acentuadamente abaixo de seu valor, provocando um arrocho salarial entre os trabalhadores que ainda continuam a ter o 'privilégio' de vender sua força de trabalho e a serem explorados, num processo infindável e ininterrupto. O que se assiste aqui é uma dupla forma de destruição da força de trabalho. De um lado, a força de trabalho supérflua, que foi produzida pelos trabalhadores como valor de troca, mas que, não sendo valor de uso para o capital, é totalmente aniquilada, engrossando as estatísticas do desemprego, fenômeno que, pelas razões expostas, é insolúvel nos marcos do capitalismo. De outro lado, 
a força de trabalho ainda aproveitada e consumida pelo capital, que, tendo em vista a diminuição de seu preço tendencial e acentuadamente abaixo de seu valor, não consegue se reproduzir a não ser de forma atrofiada e débil, comprometendo sua própria condição de produtora de mais-valia e de capital. Esses dois lados da mesma moeda, desemprego e arrocho salarial, expressam, em sua relação umbilical e orgânica, a destruição necessária da força de trabalho realizada pelo capital. Aqui se pode vislumbrar uma das grandes contradições do processo de acumulação, pois para se produzir e se reproduzir, o capital é obrigado a destruir força humana de trabalho, e ao fazê-lo destrói sua única fonte de criação (25). Soma-se a esta contradição, numa relação também contraditória, a contradição apontada anteriormente entre o capital e os capitais privados, e constata-se, como resultado desta equação, que o capital produz sua vida com a condição de produzir sua morte.

A produção de uma maior quantidade de valores de uso, que constitui o conjunto da riqueza de uma sociedade, para a satisfação das necessidades humanas com o menor quantum possível de trabalho, de dispêndio de energia humana, é o elemento propulsor do movimento de produção e reprodução do capital e, ao mesmo tempo, o fator de seu próprio aniquilamento. O desenvolvimento das forças produtivas propicia, a um só tempo, a vida e a morte do capital. Trata-se, no fundo, da contradição imanente e inexterminável, no capitalismo, entre a valorização do valor, o capital, e o valor de uso, a riqueza; entre o trabalho produtivo de capital e o trabalho concreto; entre o capital e a satisfação das necessidades humanas (26); entre o capital hominizado e o ser social reificado; em suma, entre o capital e a humanidade (27). Uma leitura cuidadosa do conjunto da obra $O$ Capital permitiria inferir que Marx se empenhou em apreender a constituição histórica desta contradição, inclusive porque já a havia indicado embrionariamente no capítulo primeiro ao destacar a contradição entre o trabalho concreto e o trabalho abstrato, ou seja, entre o valor de uso e o valor (28) (cf. op. cit.:52-3). Tal contradição não teria se convertido na expressão da luta de vida e morte da humanidade não fosse a necessidade de acumulação do valor, ou seja, da produção e reprodução do capital.

Portanto, se o trabalho, numa forma social genérica, é "um processo entre o homem e a Natureza, um processo em que o homem, por sua própria ação, media, regula e controla seu metabolismo com a Natureza" (Marx, 1983:149), ou seja, é o elemento determinante na constituição da própria natureza humana, no capitalismo a construção do gênero humano, por intermédio do trabalho, se dá pela sua destruição, sua emancipação se efetiva pela sua degradação, sua liberdade ocorre pela sua escravidão, a produção de sua vida se realiza pela produção de sua morte (29). Na forma social do capital, a construção do ser humano, por meio do trabalho, se processa pela sua niilização, a afirmação de sua condição de sujeito se realiza pela negação desta mesma condição, sua hominização se produz pela produção de sua reificação. No limite, trata-se da constituição do fetiche do capital - o capital que se subjetiviza ou se hominiza reificando as relações sociais e o ser social - ou, como procurei demonstrar em outro texto (Tumolo, 2003), da subsunção real da vida social ao capital. Depois de ter desvelado o enigma do fetiche da mercadoria e do dinheiro, penso que Marx tinha como objetivo, em O Capital — obra que ficou inconclusa — - desvendar o segredo do fetiche do capital.

No que diz respeito ao tema central examinado neste texto, o significado do trabalho na forma social do capital, a análise desenvolvida até aqui nos permite extrair, entre outras, três grandes conclusões, que estão, resumidamente, assinaladas abaixo.

1. Em O Capital, Marx pretende apreender não o ser social genérico de uma forma social genérica, mas o ser social de uma forma social historicamente determinada, a forma capital. Por isso, todas as categorias analíticas que compõem seu construto teórico, sintetizadas na categoria 'capital', têm como finalidade apreender este ser histórico-social.

2. A utilização, no início do capítulo cinco, de categorias analíticas de caráter genérico, como o trabalho em geral, significou um recurso metodológico, cujo objetivo foi o de apresentar as características e fatores constitutivos do processo de trabalho, diferenciando-o do processo de valorização e, ao mesmo tempo, compreendendo, como unidade de ambos, o processo de produção capitalista. Dessa forma, a categoria 'trabalho', entendida aqui, por suposto, como trabalho em geral, não serve ou, na melhor das hipóteses, é insuficiente para a apreensão da relação capitalista de produção e, portanto, do ser social da forma capital.

3. Penso que na obra O Capital, a rigor, 'trabalho' dificilmente pode ser considerado como categoria analítica. Ele aparece como 'trabalho em geral' numa forma social genérica e como 'trabalho concreto', 'trabalho abstrato' e 'trabalho produtivo' (de capital) na forma social capitalista (30). Mais do que apontar a relação de determinação entre as três categorias de trabalho no capitalismo, procurei evidenciar, neste texto, a relação de contradição entre o trabalho concreto, como criador do valor de uso para satisfação das necessidades humanas, e o trabalho produtivo de capital, cuja análise conduziu à conclusão segundo a qual, na forma social do capital, a dimensão de positividade do trabalho se constitui pela dimensão de sua negatividade (31), seu estatuto de ser criador da vida humana se constrói por meio de sua condição de ser produtor da morte humana. 
Dado o conjunto de razões expostas, o trabalho não pode ser considerado como princípio educativo de uma estratégia político-educativa que tenha como horizonte a transformação revolucionária da ordem do capital. O trabalho só poderia ser concebido como princípio balizador de uma proposta de educação que tenha uma perspectiva de emancipação humana numa sociedade baseada na propriedade social, vale dizer, na nãopropriedade dos meios de produção que, dessa forma, teria superado a divisão e a luta de classes e, por conseguinte, qualquer forma de exploração social, bem como o trabalho produtivo de capital e o trabalho abstrato (32), porque teriam sido eliminados o capital e o mercado. Tratar-se-ia de uma sociedade que, fundada no trabalho como elemento mediador da relação metabólica entre os seres humanos e a natureza, teria como objetivo a produção de riquezas para a satisfação de todas as necessidades humanas, do estômago à fantasia. Penso, entretanto, que, se algum dia a humanidade lograr construir uma sociedade nesses moldes, o que, a rigor, é apenas uma possibilidade histórica e não uma condição determinística, talvez o prazer seja princípio educativo e não o trabalho, tendo em vista que, se este não poderia ser eliminado de todo, seria tendencial e acentuadamente minimizado em favor do prazer de viver. Porém, tanto a respeito deste assunto como de outros referentes a tal hipotética sociedade, não é possível, neste momento, oferecer "receitas para as cozinhas do futuro". Enquanto os seres humanos viverem sob a égide do capital e de seu modo de produção, o capitalismo, o trabalho não pode ser princípio educativo de uma concepção de educação que pretenda a emancipação humana. Se se pode falar, neste caso, de um princípio educativo, este deveria ser, dentro da compreensão aqui arrolada, a 'crítica radical do trabalho', que implica a 'crítica radical do capital e do capitalismo'.

\section{NOTAS}

1 Exemplo da importância que o trabalho como princípio educativo adquire pode ser encontrado, entre outros, no Caderno de Princípios da Educação do MST (MST, 1999).

2 Vide, p. ex., o documento Bases do projeto político pedagógico do programa de educação profissional da CUT - Brasil (CUT/SNF, s.d.), principalmente o capítulo sobre os princípios metodológicos (p. 35 ss.). Vide, também, o caderno que serve como subsídio teórico-político para as atividades do projeto Formação Integral, um dos principais programas de formação profissional da CUT, denominado Trabalho e educação num mundo em mudanças - Caderno de apoio às atividades de Formação do Programa Nacional de Formação de Formadores e Capacitação de Conselheiros, onde está contido o artigo de Saviani intitulado O trabalho como princípio educativo frente às novas tecnologias (Saviani, 1998), publicado originalmente em Ferretti (org.), 1994.

$3 \mathrm{O}$ autor deste texto foi convidado para fazer uma conferência e um debate sobre "O trabalho como princípio educativo" numa das escolas da CUT, em 1999. Depois da análise e aberto o debate, um dos educadores da escola afirmou que pensava que trabalho como 'princípio' educativo significava que o educador deveria 'iniciar' sua atividade educativa, com um público de trabalhadores, pedindo que estes falassem acerca de sua realidade de 'trabalho'.

4 Vide, p. ex., Arroyo (1987); Arruda (1987); Ferretti \& Madeira (1992); Ferretti (org.) (1996); Franco, L.A.C. (1986 e 1987); Franco, M.L.P.B. (1989); Frigotto (1987, 1989, 1998); Gomes (1987); Kuenzer (1986a, 1987, 1988, 1988a, 1989); Machado (1989); Nosella (1987 e 1989); Saviani (1986a, 1989, 1991, 1994).

5 Um estudo deste tipo pode ser encontrado em outro texto de minha autoria: Tumolo (1996).

6 Para Marx, é "necessário distinguir o método de exposição, formalmente, do método de pesquisa. A pesquisa tem de captar detalhadamente a matéria, analisar as suas várias formas de evolução e rastrear sua conexão íntima. Só depois de concluído esse trabalho é que se pode expor adequadamente o movimento real. Caso se consiga isso, e espelhada idealmente agora a vida da matéria, talvez possa parecer que se esteja tratando de uma construção a priori” (Marx, $1983: 20)$.

7 Para Moura (1999:67), "passa inadvertido a grande número de comentaristas o fato de que a arquitetura argumentativa de O Capital inicie-se pela noção de 'riqueza' (Reichtum) e não pela de 'mercadoria' (Ware), como aos mais afoitos pudera parecer".

8 A obra central deste autor é o resultado de um estudo a respeito da natureza e das causas da riqueza das nações.

9 O próprio autor reconhece que este capítulo é o que oferece maior dificuldade de compreensão (cf. Marx, $1983: 11)$. 
10 Em O Capital, é neste capítulo que Marx menciona pela primeira vez a categoria "mais-valia". Contudo, ele escolhe o caminho segundo o qual primeiro explica de onde ela 'não' se origina — da circulação simples de mercadorias - , para depois, na segunda parte do capítulo cinco, demonstrar de onde efetivamente se origina.

11 Não se pode confundir o valor da força de trabalho com o valor por ela produzido a partir do consumo de seu valor de uso.

12 A esse respeito, Marx afirma que "para reter o ouro como dinheiro e, portanto, como elemento de entesouramento, é necessário impedi-lo de circular ou de dissolver-se como meio de compra, em artigos de consumo. O entesourador sacrifica, por isso, ao fetiche do ouro os seus prazeres da carne. Abraça com seriedade o evangelho da abstenção. Por outro lado, somente pode subtrair da circulação em dinheiro o que a ela incorpora em mercadoria. Quanto mais ele produz, tanto mais pode vender. Laboriosidade, poupança e avareza são, portanto, suas virtudes cardeais, vender muito e comprar pouco são o resumo de sua economia política". Note-se que tal análise pode ser considerada como uma crítica "antecipada" de um dos argumentos centrais apresentado por Weber no seu clássico "A ética protestante e o espírito do capitalismo" (Weber, 1985), publicado no início do século XX. Nesse sentido, do ponto de vista da análise marxiana, a ética protestante poderia servir como elemento alavancador do espírito do 'entesourador' e não do espírito do 'capitalista', tendo em vista que aquele é a negação deste último.

13 Se for possível imaginar um esqueleto resumido do método de exposição nos quatro primeiros capítulos, ele apresentar-se-ia aproximadamente como o que está abaixo:

\begin{tabular}{|c|c|c|}
\hline Valor de uso (riqueza) & \multicolumn{2}{|l|}{ V. U. } \\
\hline Mercadoria & \multicolumn{2}{|l|}{ M } \\
\hline Mercadoria - Mercadoria & \multicolumn{2}{|l|}{$\mathrm{M}-\mathrm{M}$} \\
\hline Mercadoria - Dinheiro & \multicolumn{2}{|l|}{$M-D$} \\
\hline Mercadoria - Dinheiro - Mercadoria & \multicolumn{2}{|c|}{$M-D-M$} \\
\hline Mercadoria - Dinheiro Dinheiro - Mercadoria & $M-D$ & D-M \\
\hline Dinheiro - Mercadoria & & $\mathrm{D}-\mathrm{M}$ \\
\hline Dinheiro - Mercadoria - Dinheiro & & $\mathrm{D}-\mathrm{M}-\mathrm{D}$ \\
\hline Dinheiro - Mercadoria - Dinheiro + Mais-Valia (') & & D-M-D' \\
\hline
\end{tabular}

$14 \mathrm{Na}$ verdade, o autor já esboça os elementos embrionários para a apresentação do trabalho produtivo — leia-se produtivo de capital — , mas tal apresentação é 'adiada' pelas razões analisadas na seqüência.

15 É importante notar que, geralmente, a concepção de trabalho presente no lema do trabalho como princípio educativo é claramente de 'trabalho em geral', conforme se pode observar, por exemplo, na citação de Saviani (1986a:14), aqui reproduzida na pág. 2.

16 No capítulo quatorze, o próprio autor recupera o tema sobre o trabalho produtivo, citando este mesmo trecho de seu texto e a nota de rodapé. Nesse capítulo, ele dá a essa categoria um significado completamente distinto, conforme veremos adiante.

17 Não confundir com trabalho abstrato.

18 Penso que quando Marx faz a viragem metodológica no início do capítulo cinco, seu ponto de chegada, o processo simples de trabalho que tem como objetivo a produção de valor de uso (riqueza), se torna o ponto de partida da reviragem que faz na segunda parte do capítulo, reproduzindo a partir daqui a mesma direção metodológica que construiu ao longo dos quatro primeiros capítulos — do valor de uso à mais-valia e ao capital. 
19 A esse respeito, Marx enfatiza que "todas as condições do problema foram resolvidas e, de modo algum, as leis do intercâmbio de mercadorias foram violadas. Trocou-se equivalente por equivalente" (idem:160).

20 A partir do estudo das duas formas de mais-valia, absoluta e relativa, o autor analisa a transição da subsunção formal para a subsunção real do trabalho ao capital, já que a mais-valia relativa supõe uma forma especificamente capitalista. A esse respeito, além das obras do próprio autor, vide Tumolo, 2003.

21 O parágrafo e a nota de rodapé estão reproduzidos neste texto, na pág. 11.

$22 \mathrm{O}$ autor desenvolve este assunto no Capítulo sexto inédito de O capital e no Teorias da mais-valia.

\section{Marx denomina de "divisão manufatureira do trabalho".}

24 Contestando o pensamento vulgar, o capitalismo não é uma sociedade de consumo, mas, ao contrário, tal forma social tem como objetivo a acumulação, que é exatamente o oposto do consumo. Contudo, diferentemente do que se possa imaginar, não se trata de acúmulo de riqueza - valor de uso - , ou de dinheiro, e sim de acumulação de 'valor'.

25 Num dos textos mais importantes de sua vasta obra, Habermas sugere que a força de trabalho não é a única fonte de mais-valia. Para ele, "a ciência e a técnica transformam-se na primeira força produtiva e caem assim as condições de aplicação da teoria marxiana do valor-trabalho. Já não mais tem sentido computar os contributos ao capital para investimentos na investigação e no desenvolvimento sobre a base do valor da força de trabalho não qualificada (simples), se o progresso técnico e científico se tornou uma fonte independente de mais-valia frente à fonte de mais-valia que é a única tomada em consideração por Marx: a força de trabalho dos produtores imediatos tem cada vez menos importância" (Habermas, 1994:72-3). Ora, Marx não considerou, e não poderia considerar, o progresso técnico e científico como fonte de mais-valia, mas somente a força de trabalho, porque, em seu arcabouço teórico, o substrato de valor e, por conseguinte, também de mais-valor (ou mais-valia), é trabalho humano abstrato, dispêndio de força de trabalho humana. Justamente por causa disso é que o desenvolvimento das forças produtivas, incluído aqui o progresso técnico e científico, entra em contradição com o valor, de tal forma que o crescimento da força produtiva do trabalho diminui a grandeza do valor de uma massa provavelmente maior de valores de uso. $O$ desenvolvimento das forças produtivas é diretamente proporcional à quantidade de valores de uso criados e inversamente proporcional à grandeza de valor produzida. Disso resulta o conjunto de contradições assinaladas neste ensaio. A citação de Habermas (acima) demonstra a compreensão problemática - para dizer o mínimo - que tem acerca das categorias de mais-valia e de valor em Marx, que, como se sabe, constituem a "pedra angular" da teoria marxiana.

26 Embora se deva reconhecer que a realização do capital ocorra na esfera da circulação e, por desdobramento, na esfera do consumo, sua criação e recriação se efetivam na esfera da produção do capital. Contudo, há uma contradição entre essas duas esferas, uma vez que, se o consumo de valores de uso para a satisfação das necessidades humanas é condição de existência do capital, é, ao mesmo tempo, condição de seu aniquilamento.

27 Tal análise permite a compreensão, na agudeza necessária, da lógica destrutiva do capital. Sugiro que, acima de tudo, deva ser entendida como lógica destrutiva do ser social.

28 Penso que a análise da contradição entre valor de uso e valor seja mais importante do que o estudo da contradição entre valor de uso e valor de troca, uma vez que aquela já expressa, ainda que embrionariamente, a contradição fundamental do capital apontada acima.

29 Por outro lado, supõe-se, em suma, que a produção de sua morte possibilita a produção de sua vida.

30 Se me for permitido fazer esse tipo de especulação, diria que, em O Capital, o 'trabalho', em seus diversos conteúdos de concretização no capitalismo, não poderia ser considerado como a categoria analítica principal. Se alguma categoria ocupa este posto, eu arriscaria dizer que é o 'capital'.

31 Neste sentido, me parece insuficiente certo tipo de abordagem que menciona estas duas dimensões do trabalho, positividade e negatividade, sem compreendê-las como componentes de uma relação de contradição. Neste caso, tratar-se-ia muito mais dos dois pólos da mesma contradição do que de duas dimensões.

32 Creio que também seria superado o trabalho concreto, pois, a rigor, a existência desta categoria analítica 
só se justifica em relação e oposição ao trabalho abstrato. Como este seria superado, a existência daquele perderia sentido.

\section{PAULO SERGIO TUMOLO}

Doutor em Educação: História e Filosofia da Educação (PUC-SP). Professor Adjunto do Centro de Ciências da Educação e do Programa de Pós-Graduação em Educação da Universidade Federal de Santa Catarina.

\section{REFERÊNCIAS BIBLIOGRÁFICAS}

ANTUNES, Ricardo (1995). Adeus ao trabalho? Ensaio sobre as metamorfoses e a centralidade do mundo do trabalho. São Paulo : Cortez/UNICAMP. $\overline{\text { Boitempo. }}$

(1999). Os sentidos do trabalho. Ensaio sobre a afirmação e a negação do trabalho. São Paulo :

ARROYO, Miguel Gonzales (1987). O direito do trabalhador à educação. In: GOMES, Carlos M. et alii. Trabalho e conhecimento: dilemas na educação do trabalhador. São Paulo: Cortez/Autores Associados. $\overline{\mathrm{APEOESP}}$.

(1989). Trabalho, educação, escola, LDB (Debate). Revista de Educação, n. 4, p. 4-12. São Paulo:

ARRUDA, Marcos (1987). A articulação trabalho-educação visando uma democracia integral. In: GOMES, Carlos M. et alii. Trabalho e conhecimento: dilemas na educação do trabalhador. São Paulo: Cortez/Autores Associados.

BAETHGE, Martin (1994). Trabalho, socialização, identidade - a crescente subjetivação normativa do trabalho. In: MARKERT, Werner (org.) Teorias da educação do iluminismo, conceitos de trabalho e do sujeito. Rio de Janeiro: Tempo Brasileiro.

CATANI, Antonio David (1995). Processo de trabalho e novas tecnologias. Porto Alegre : Editora da Universidade/UFRGS. Processo de trabalho e novas tecnologias.

\section{UFRGS.}

(Org.) (1997). Trabalho e tecnologia. Dicionário crítico. Petrópolis/Porto Alegre : Vozes/Editora da

CENTRAL ÚNICA DOS TRABALHADORES (1993) Trabalhadores e Educação: Organização e Construção da Cidadania. In: Cadernos ANDES no. 10 - Educação e Trabalho, Brasília.

(1995) Resoluções da 7ª. Plenária Nacional Zumbi dos Palmares. In: InformaCUT, no. 257

. (1997). Avaliação externa da política nacional de formação da CUT. São Paulo : Xamã.

CENTRAL ÚNICA DOS TRABALHADORES / SECRETARIA NACIONAL DE FORMAÇÃO. (1998) Trabalho e educação num mundo em mudanças. Caderno de apoio às atividades de Formação do Programa Nacional de Formação de Formadores e Capacitação de Conselheiros. Ed. Autor.

$\overline{\text { Ed. Autor. }}$

(s.d.). Bases do projeto político pedagógico do programa de educação profissional da CUT - Brasil.

DEDECCA, Claudio Salvadori (1998). Educação e trabalho no Brasil: mais mitos que realidade. In: CUT/SNF. Trabalho e educação num mundo em mudanças. Caderno de apoio às atividades de Formação do Programa Nacional de Formação de Formadores e Capacitação de Conselheiros. Ed. Autor, pp.78-80.

FERRETTI, Celso J. (1987). Trabalho e orientação profissional. São Paulo: PUC-SP. (Tese de doutoramento).

FERRETTI, Celso J. \& MADEIRA, Felícia R. (1992). Educação/trabalho: reinventando o passado? Cadernos de Pesquisa, n. 80, p. 75-86. São Paulo : Fundação Carlos Chagas. 
FERRETTI, Celso. J. et alii (org.) (1994). Novas tecnologias, trabalho e educação: um debate multidisciplinar. Petrópolis : Vozes.

FERRETTI, Celso. J. et alii (org.) (1999). Trabalho, formação e currículo. Para onde vai a escola? São Paulo : Xamã.

FIDALGO, Fernando Selmar (org). (1996) Gestão do trabalho e formação do trabalhador. Belo Horizonte : Movimento de Cultura Marxista.

FRANCO, Luis Antonio de Carvalho (1986). A educação do trabalho e o trabalho da educação. Bimestre, n. 1, out. São Paulo: MEC/INEP - Cenafor.

. (1987). A escola do trabalho e o trabalho da escola. São Paulo: Cortez/Autores Associados.

FRANCO, Maria Laura P. B. (1989). Possibilidades e limites do trabalho enquanto princípio educativo. Cadernos de Pesquisa, n. 68, p. 29-38. São Paulo: Fundação Carlos Chagas.

FRIGOTTO, Gaudêncio (1986). A produtividade da escola improdutiva: um (re)exame das relações entre educação e estrutura econômico-social capitalista. 2. ed. São Paulo: Cortez/Autores Associados.

. (1987). Trabalho, conhecimento, consciência e a educação do trabalhador: impasses teóricos e práticos. In: GOMES, Carlos M. et alii. Trabalho e conhecimento: dilemas na educação do trabalhador. São Paulo: Cortez/Autores Associados.

. (1989). Um conceito que gera polêmicas. Leia. São Paulo, ano XI (129): 52-53, jul. (entrevista).

. (1993). Trabalho-educação e a crise do capitalismo: ajuste neoconservador e alternativa democrática. Rio de Janeiro: UFF (Tese apresentada no concurso de professor titular).

. (1994) Capital humano e sociedade do conhecimento: concepção neoconservadora de qualidade na educação. Contexto e Educação, n. 34, p. 7-28..

. (1998). Educação, crise do trabalho assalariado e do desenvolvimento: teorias em conflito. In: . (org.). Educação e crise do trabalho: perspectivas de final de século. Petrópolis : Vozes.

. (2000). Educação e a crise do capitalismo real. $4^{\mathrm{a}}$. ed. São Paulo : Cortez.

Globalização aprofunda o abismo entre ricos e pobres. Folha de S. Paulo, 02/11/97, especial 12.

GOMES, Carlos M. (1987). Processo de trabalho e processo de conhecimento. In: GOMES, C. M. et alii. Trabalho e conhecimento: dilemas na educação do trabalhador. São Paulo: Cortez/Autores Associados.

GRAMSCI, Antonio (1986). Concepção dialética da história. 6. ed. Rio de Janeiro: Civilização Brasileira.

HABERMAS, Jürgen. (1994) Técnica e Ciência como "Ideologia". In.: "Ideologia". Lisboa : Edições 70. Técnica e Ciência como

HARVEY, David (1993). A condição pós-moderna. São Paulo : Loyola.

KONIG, Helmut (1994). "A crise da sociedade do trabalho e o futuro do trabalho: crítica de um debate atual". In.: MARKERT, Werner (org.). Teorias de educação do iluminismo, conceitos de trabalho e sujeito. Rio de Janeiro : Tempo Brasileiro.

KUENZER, Acácia Zeneida (1986). O aluno trabalhador e o ensino profissionalizante. Bimestre, n. 1. São Paulo: MEC/INEP - Cenafor.

. (1986a) Pedagogia da fábrica: as relações de produção e a educação do trabalhador. São Paulo:

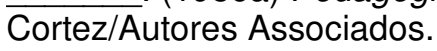


(1987) Educação e trabalho no Brasil: o estado da questão. Brasília: REDUC/INEP.

. (1988). Ensino de 2º grau: o trabalho como princípio educativo. São Paulo: Cortez.

. (1988a) A escola de $2^{\circ}$ grau na perspectiva do aluno trabalhador. Caderno CEDES(20): 48-55. São Paulo: Cortez/Cedes.

. (1989). O trabalho como princípio educativo. Cadernos de Pesquisa (68): 21-28. São Paulo:

Fundação Carlos Chagas.

LOPES NETO, Sebastião \& MORAES, Carmem Sylvia Vidigal (1993). "Contribuição para a definição de uma Política de formação profissional da CUT". In.: Cadernos ANDES no. 10 - Educação e Trabalho. Brasília.

MACHADO, Lucilia R. de Souza (1989). Politecnia, escola unitária e trabalho. São Paulo: Cortez/Autores Associados.

$\overline{A P E O E S P}$.

. (1989a) Trabalho, tecnologia e ensino politécnico. Revista de Educação, n. 4, p. 26-30. São Paulo:

MANACORDA, Mário A. (1977). El princípio educativo em Gramsci. Salamanca : Sígueme.

. (1991). Humanismo de Marx e industrialismo de Gramsci. In: SILVA, Thomaz T. (org.) Trabalho, educação e prática social. Porto Alegre: Artes Médicas.

MARX, Karl. (1970). Manuscritos econômicos e filosóficos. In: FROMM, Erich. Conceito marxista do homem. $5^{\mathrm{a}}$ ed., R. Janeiro : Zahar Editores

(1974a). Prefácio de Para a crítica da economia política. In: Manuscritos econômicos filosóficos e outros textos escolhidos. São Paulo, Abril Cultural, p. 133-138. (Os Pensadores).

. (1974b). O Método da Economia Política. In.: . Manuscritos econômico-filosóficos e outros textos escolhidos. São Paulo : Abril Cultural.

. (1974c). Para a crítica da economia política. In: . Manuscritos econômicos filosóficos e outros textos escolhidos. São Paulo, Abril Cultural, p. 107-263. (Os Pensadores).

. (1974d). Manuscritos econômico-filosóficos. In: . Manuscritos econômico-filosóficos e outros textos escolhidos. São Paulo : Abril Cultural.

. (1983). O Capital. Vol. I, tomo 1, São Paulo : Abril Cultural.

$\overline{\text { Cultural. }}$

(1983a). Posfácio da segunda edição. In: O Capital. Vol. I, tomo 1, São Paulo : Abril

. (1984). O Capital. Vol. I, tomo 2, São Paulo : Abril Cultural.

. (1988). As crises econômicas do capitalismo. São Paulo: Acadêmica.

. (s.d.). Capítulo VI inédito de O Capital. São Paulo : Moraes.

MARX, Karl \& ENGELS, Friedrich. (1987). A ideologia alemã (Feuerbach). 6. ed. São Paulo: Hucitec. . (1983). Textos sobre educação e ensino. São Paulo: Moraes.

MANDEL, Ernest (1990). A crise do capital: os fatos e sua interpretação marxista. São Paulo : UNICAMP/Ensaio.

MOURA, Mauro Castelo Branco de. (1999). Sobre o projeto de crítica da economia política de Marx. Crítica marxista, São Paulo, n. 9, pp. 52-78.

file://C:LDocuments and Settings\AdministradorlMeus documentos\Minhas Webs\NED... 28/8/2008 
MST. (1999). Princípios da educação no MST. Caderno de Educação no 8. S. Paulo : MST

NAPOLEONI, Claudio (1981). Lições sobre o capítulo sexto (inédito) de Marx. São Paulo : Ciências Humanas.

NOSELLA, Paolo (1987). Trabalho e educação. In: GOMES, Carlos M. et alii. Trabalho e conhecimento: dilemas na educação do trabalhador. São Paulo: Cortez/Autores Associados.

. (1989) O trabalho como princípio educativo em Gramsci. In: Revista de Educação, n. 4, p. 16-25. São Paulo: APEOESP.

OFFE, Claus. (1994). Trabalho: a categoria sociológica chave? In: . Capitalismo desorganizado.

São Paulo: Brasiliense.

PARO, Vitor Henrique. (1999). Parem de preparar para o trabalho!!! Reflexões acerca dos efeitos do neoliberalismo sobre a gestão e o papel da escola básica. In: FERRETTI, Celso. J. et alii (org.) (1999). Trabalho, formação e currículo. Para onde vai a escola? São Paulo : Xamã.

PISTRAK. (1981). Fundamentos da escola do trabalho. São Paulo: Brasiliense.

RUBIN, Isaak Illich (1987). A teoria marxista do valor. São Paulo : Polis.

SALM, Claudio Leopoldo (1980). Escola e trabalho. São Paulo: Brasiliense.

SAVIANI, Dermeval (1984). Educação: do senso comum à consciência filosófica. 4. ed. São Paulo: Cortez/Autores Associados.

. (1986). Escola e democracia. 12. ed. São Paulo: Cortez/Autores Associados.

. (1986a) O nó do ensino de $2^{\circ}$ grau. Bimestre, n. 1. São Paulo: MEC/INEP - Cenafor. APEOESP.

(1989). Repensando a relação trabalho-escola. In: Revista de Educação, n. 4, p. 13-16. São Paulo: Associados.

(1991). Pedagogia histórico-crítica. Primeiras aproximações. $2^{a}$. ed., São Paulo : Cortez/Autores

. (1994). O trabalho como princípio educativo frente às novas tecnologias. In: FERRETTI, Celso. J. et alii (org.). Novas tecnologias, trabalho e educação: um debate multidisciplinar. Petrópolis : Vozes.

(1998). O trabalho como princípio educativo frente às novas tecnologias. In: CUT/SNF. Trabalho e educação num mundo em mudanças. Caderno de apoio às atividades de Formação do Programa Nacional de Formação de Formadores e Capacitação de Conselheiros. Ed. Autor, pp.81-88.

TEIXEIRA, Francisco José S. (1995) Pensando com Marx. Uma leitura crítico-comentada de O capital. São Paulo : Ensaio.

TUMOLO, Paulo Sergio. (1991). Educação e hegemonia no Brasil. Notas para uma reflexão crítica. São Paulo : PUC/SP (Dissertação de Mestrado)

. (1996). Trabalho: categoria sociológica chave e/ou princípio educativo? O trabalho como princípio educativo diante da crise da sociedade do trabalho. Perspectiva, n. 26/39-70. Florianópolis : UFSC/CED.

. (1998). O novo padrão de acumulação de capital e a formação sindical da Central Única dos Trabalhadores. Redes, v.3, n.1, p.65-84, Santa Cruz do Sul : UNISC.

. (1999). A CUT e a formação profissional: esboço de análise crítica. Trabalho \& Crítica (Anuário do GT Trabalho e Educação da ANPEd), no 1/98-112. Niterói/Belo Horizonte : EdUFF/NEDDATE-UFF/NETEUFMG, Setembro/1999. 
(2000). O significado do trabalho no mundo capitalista (The meaning of the work in the capitalism world). RIDEF 2000 (Rencontre Internationale des Educateurs Freinet) Isper - Austria, Julho 2000.

(2001). Reestruturação produtiva no Brasil: um balanço crítico introdutório da produção bibliográfica. Educação \& Sociedade, Campinas, n.77, p.71-99.

(2002). Da contestação à conformação. A formação sindical da CUT e a reestruturação capitalista. Campinas: Unicamp.

. (2003). Trabalho, vida social e capital na virada do milênio: apontamentos de interpretação. Educação \& Sociedade, Campinas - SP, v. 24, n. 82, p. 159-178.

WEBER, Max. (1985). A ética protestante e o espírito do capitalismo. 4a․ ed., São Paulo : Pioneira.

file://C: Documents and Settings\AdministradorlMeus documentos\Minhas Webs\NED... 28/8/2008 